\title{
Perfil clínico-epidemiológico de portadores de HIV atendidos pelo Serviço de Atendimento Especializado em Centro de Testagem e Aconselhamento
}

\author{
Clinical-epidemiological profile of HIV carriers assisted by Specialized Care Service at the \\ Testing and Counseling Center
}

\author{
Perfil clínico-epidemiológico de los portadores de HIV atendidos por el Servicio de \\ Atención Especializada em Pruebas y Centro de Asesoramiento
}

Maria Stéphanny de Souza Silva ${ }^{1}$, Orlando Augusto de Morais Miranda ${ }^{2}$, Diana Ramos Cavalcanti ${ }^{3}$, Julyana Viegas Campos ${ }^{4}$, Danilo Ramos Cavalcanti* ${ }^{4 *}$

\section{RESUMO}

Objetivo: Avaliar os aspectos sociodemográficos e clínicos de pacientes com HIV atendidos pelo Serviço de Atendimento Especializado em Centro de Testagem e Aconselhamento. Métodos: Trata-se de um estudo epidemiológico descritivo, do tipo transversal, realizado através da obtenção de dados secundários fornecidos pelo Serviço de Atendimento Especializado em um Centro de Testagem e Acolhimento, no qual foram analisados os aspectos sociodemográficos e aspectos laboratoriais dos portadores de HIV. Resultados: No período estudado, foi observado que 356 indivíduos realizavam tratamento, sendo prevalente o sexo masculino $(58,7 \%)$. Observou-se que 153 pacientes apresentaram carga viral menor que 50 cópias $/ \mathrm{mL}$, totalizando $80,1 \%$, sendo o grupo com maior prevalência. Foi analisada a contagem de linfócitos TCD4+, no qual o sexo masculino esteve predominante com $52 \%$, apresentando uma variação de 71 a 339 células $/ \mathrm{mm}^{3}$. Conclusão: Diante do exposto, pelo fato de pessoas do sexo masculino apresentar maior prevalência de casos de HIV no município, fazem-se necessárias ações de conscientização por meio de redes sociais, ambulatoriais, assistenciais e educativas para esse público.

Palavras-chave: Epidemiologia, HIV, Saúde pública.

\begin{abstract}
Objective: To evaluate the sociodemographic and clinical aspects of patients with HIV treated by the Specialized Care Service at a Testing and Counseling Center. Methods: This is a descriptive, crosssectional epidemiological study, carried out by obtaining secondary data provided by the Specialized Care Service in a Testing and Reception Center, in which the sociodemographic and laboratory aspects of HIV patients were analyzed. Results: During the study period, it was observed that 356 individuals were undergoing treatment, with a predominance of males (58.7\%). It was observed that 153 patients had a viral load lower than 50 copies $/ \mathrm{mL}$, totaling $80.1 \%$, being the group with the highest prevalence. The TCD4+ lymphocyte count was analyzed, in which the male sex was predominant with $52 \%$, with a variation of 71 to $339 \mathrm{cells} / \mathrm{mm}^{3}$. Conclusion: Given the above, because males have a higher prevalence of HIV cases in the city, awareness-raising actions are needed through social, outpatient, care and educational networks for this public.
\end{abstract}

Keywords: Epidemiology, HIV, Public health.

\footnotetext{
1 Universidade Federal de Pernambuco (UFPE), Recife - PE.

2 Instituto Aggeu Magalhães/FIOCRUZ, Recife - PE.

${ }^{3}$ Faculdade Integrada Tiradentes (FITS), Jaboatão dos Guararapes - PE.

${ }^{4}$ Centro Universitário da Vitória de Santo Antão (UNIVISA), Vitória de Santo Antão - PE.

*E-mail: danilorc16@gmail.com
} 


\section{RESUMEN}

Objetivo: Evaluar los aspectos sociodemográficos y clínicos de los pacientes con HIV atendidos por el Servicio de Atención Especializada en un Centro de Pruebas y Asesoramiento. Métodos: se trata de un estudio epidemiológico descriptivo, transversal, realizado a partir de la obtención de datos secundarios proporcionados por el Servicio de Atención Especializada en un Centro de Ensayo y Recepción, en el que se analizaron los aspectos sociodemográficos y de laboratorio de los pacientes con HIV. Resultados: Durante el período de estudio se observó que 356 individuos estaban en tratamiento, con predominio del sexo masculino $(58,7 \%)$. Se observó que 153 pacientes tenían carga viral menor a 50 copias $/ \mathrm{mL}$, totalizando $80,1 \%$, siendo el grupo de mayor prevalencia. Se analizó el recuento de linfocitos TCD4+, en el que predominó el sexo masculino con $52 \%$, con una variación de 71 a 339 células / $\mathrm{mm}^{3}$. Conclusión: Dado lo anterior, debido a que los hombres tienen una mayor prevalencia de casos de VIH en la ciudad, se requieren acciones de sensibilización a través de redes sociales, ambulatorias, asistenciales y educativas para este público.

Palabras clave: Epidemiología, HIV, Salud pública.

\section{INTRODUÇÃO}

O Vírus da Imunodeficiência Humana (HIV), taxonomicamente, pertence a família Retroviridae, subfamília Orthoretrovirinae e gênero Lentivirus. Tais enquadramentos nessa classificação se devem ao curso leve da infecção. Por meio de estudos sorológicos, foram evidenciados dois tipos de antígenos para este vírus: HIV-1, sendo o mais virulento e de maior disseminação e, o HIV-2, caracterizando-se por apresentar menor patogenicidade em relação ao HIV-1 (SANTOS NS, et al., 2021).

O HIV é um retrovírus constituído por uma fita de RNA simples, que infecta os linfócitos TCD4+ por meio da sua interação com as glicoproteínas presentes na membrana plasmática. Esta interação produz alteração na quantidade de linfócitos no organismo do indivíduo, geralmente apresentando números inferiores a 200 células $/ \mathrm{mm}^{3}$ no sangue. Isso ocasiona o comprometimento do sistema imunológico, fazendo com que o portador se torne susceptível a infecções oportunistas e ao desenvolvimento de neoplasias (COELHO AVC, et al., 2019; CRUZ KO, 2017; MENEZES AMF, et al., 2018; SAINI N, et al., 2019).

$\mathrm{O}$ antígeno HIV-1 apresenta uma grande diversidade genética e se divide, filogeneticamente, em quatro grupos distintos: $\mathrm{M}, \mathrm{O}, \mathrm{N}$ e $\mathrm{P}$. Além disso, apresenta cerca de cem formas recombinantes circulantes e múltiplas dentro do grupo principal, o M. Essa variedade de subtipos aumenta a probabilidade de infecções mistas, que podem promover novos e diversificados recombinantes circulares (ABONGWA LE, et al., 2019).

É importante destacar que esse vírus é proveniente da região subsaariana da África. Sua transmissão ocorre, principalmente, por relações sexuais desprotegidas. Outras formas de transmissão podem ocorrer por meio de transfusões sanguíneas, compartilhamento de seringas e transmissão vertical (por meio da mãe infectada para o filho durante o parto ou amamentação) (COELHO AVC, et al., 2019; MENEZES AMF, et al., 2018). Vale ressaltar que a transmissão vertical é uma causa importante de mortalidade infantil e, estima-se que aproximadamente dois milhões de crianças estão infectadas com HIV-1 em todo o mundo (COELHO AVC, et al., 2019).

Cerca de $40 \%$ a $90 \%$ das infecções pelo HIV, geralmente, causam sintomas inespecíficos nos pacientes. O aparecimento das manifestações clínicas caracteriza o quadro de Síndrome da Imunodeficiência Adquirida (AIDS), que representa a fase mais avançada e sintomática do portador do vírus HIV. Os sintomas típicos que este patógeno pode causar incluem quadros leves, como: febre, erupções cutâneas e linfadenopatias. Nos casos mais graves pode ocorrer comprometimento neurológico (CRUZ KO, 2017; NICOLÁS D, et al., 2019).

Diante disso, se faz necessário o diagnóstico precoce desta patologia para que ocorra a confirmação do caso. Uma vez confirmado o diagnóstico, o paciente deverá iniciar o mais rápido possível o tratamento com antirretrovirais (TARV). O diagnóstico laboratorial do HIV deve acontecer entre a terceira e quarta semana após a infecção devido aos picos de viremia, que podem ser detectados por meio da identificação do RNA viral no plasma no paciente (SANTOS NS, et al., 2021). 
O diagnóstico do HIV é realizado por meio de imunoensaios de terceira e quarta gerações, podendo também ser usados testes complementares convencionais como: western blot, imunoblot ou imunoblot rápido. Além destes, destacam-se os testes moleculares, que apresentam maior eficácia na confirmação do diagnóstico, uma vez que permitem detectar infecções agudas e/ou recentes. Os exames devem ser realizados de 2 a 3 meses após o início ou troca do tratamento com antirretrovirais em adultos e realizados com finalidade de diagnóstico em crianças menores de 18 meses (BRASIL, 2017a).

É necessário entender que a terapia com antirretrovirais possibilita ao paciente uma sobrevida, que também pode estar associada à melhoria da sua saúde, já que esta poderá estar comprometida por uma invasão viral. Portanto, para o início do tratamento, deve ocorrer a estabilização da carga viral plasmática a níveis abaixo de 50 cópias e quantidade de linfócitos TCD4+ inferiores a 500 células $/ \mathrm{mm}^{3}$ (COUTINHO MFC, et al., 2018; SOUZA HC, et al., 2020).

As estimativas da vigilância do HIV/AIDS relatam que cerca de 1,1 milhão de indivíduos estão vivendo com o vírus na América e, apesar da disponibilidade de testes, aproximadamente $15 \%$ dos indivíduos infectados permanecem sem diagnóstico (OLATOSI B, et al., 2020).

No período de 2007 até junho de 2020, segundo o Sistema de Agravos e Notificações (Sinan), foram notificados 342.459 casos de infecção pelo HIV no Brasil. A região Sudeste abrange o maior quantitativo de casos de HIV, sendo 152.029 (44,4\%) e a região Nordeste, fica em terceiro lugar com $30.943(9,0 \%)$. No ano de 2019, foram notificados 41.919 casos de infecção pelo HIV, sendo a região Nordeste a que teve o segundo maior quantitativo, totalizando 10.752 (25,6\%) (BRASIL, 2020).

Diante disto, é importante destacar que o Brasil fornece serviços que garantem a população o aconselhamento e o diagnóstico do HIV. O Centro de Testagem e Aconselhamento (CTA) é responsável pela realização dos testes para pesquisa do vírus HIV. Assim como, ligado ao mesmo pode-se encontrar o Serviço de Atendimento Especializado (SAE), que é responsável pelo acompanhamento e tratamento do paciente com HIV. Ambos estão associados aos serviços do Sistema Único de Saúde (SUS), atuando também na prevenção de outras infecções sexualmente transmissíveis (BRASIL, 2017b).

A Organização Mundial da Saúde (OMS), o Programa Conjunto das Nações Unidas para AIDS (UNAIDS) e o Ministério da Saúde do Brasil defendem a importância do diagnóstico precoce do vírus HIV, visto que garante ao indivíduo infectado iniciar o tratamento. Desde 1985 foi disponibilizado em Centros de Testagem e Aconselhamento (CTA) testes para detecção do vírus, por meio da técnica ELISA, cujo objetivo era interromper a cadeira de transmissão do vírus através do tratamento precoce. Nesse cenário, já foi identificado cerca de 380 CTAs no Brasil, sendo a maior parte localizada na Região Sudeste. É necessário salientar que os exames de diagnósticos de triagem e confirmatório para HIV são ofertados em quase todos os centros de testagem e aconselhamento. Acerca do aconselhamento fornecido para a população pode ser realizado, antes do teste sorológico de forma individual e coletiva, por profissional de nível superior (BRASIL, 2017b).

O SAE, por sua vez, realiza os exames para a determinação da quantidade de carga viral, que se dá por meio da quantidade de RNA viral no plasma do paciente, ou seja, quantifica as cópias do vírus que estão sendo produzidas e adicionadas na circulação sanguínea, bem como, a pesquisa de linfócitos TCD4+ e TCD8 (SANTOS NS, et al., 2021; BRASIL, 2017a; BRASIL, 2017b).

Desse modo, a avaliação da carga viral e o seu acompanhamento é de extrema importância para a assistência no decorrer da infecção, visto que a quantidade de RNA viral encontrada está diretamente ligada à rapidez em que a infecção progride, devido ao enfraquecimento do sistema imunológico. A contagem da carga viral varia de acordo com o estágio da infecção e com a idade do paciente. Quanto mais recente for realizada, mais elevados serão os picos da carga viral (BRASIL, 2017a).

É necessário destacar que a contagem das células CD4 é realizada de forma seriada com o objetivo de avaliar a eficácia do tratamento e, se necessário, a troca da TARV. Nesse sentido, a metodologia utilizada com maior frequência é a citometria de fluxo, sendo a ferramenta mais importante no acompanhamento da contagem de linfócitos TCD4+. Ademais, segundo o Ministério da Saúde, é recomendado que o exame de 
contagem de linfócitos TCD4+ seja realizado no mesmo laboratório devido a uma grande oscilação intra e interindividual, dificultando assim a utilização deste marcador nas fases precoces da infecção (BRASIL, 2017a; SOUZA HC, et al., 2020).

Diante disso, este trabalho teve como objetivo avaliar os aspectos sociodemográficos e clínicos de pacientes com HIV atendidos pelo Serviço de Atendimento Especializado em Centro de Testagem e Aconselhamento.

\section{MÉTODOS}

Trata-se de um estudo epidemiológico descritivo, do tipo transversal, realizado através da avaliação das fichas de acompanhamento de pacientes diagnosticados com HIV, atendidos no município de Vitória de Santo Antão - PE.

Os prontuários utilizados foram fornecidos pelo CTA/SAE. Os dados coletados foram referentes ao período de 1 de janeiro de 2017 a 30 de junho de 2020. Nesse intervalo de tempo, estavam cadastrados 356 indivíduos que recebiam atendimento no SAE por um(a) médico(a) infectologista e outros profissionais como enfermeiros, nutricionistas, psicólogos, entre outros.

Os dados sociodemográficos (gênero, idade e cidade) foram coletados de todos os indivíduos cadastrados nos anos de estudo. Contudo, as variáveis referentes aos dados laboratoriais (detecção da carga viral e contagem de células TCD4+), foram coletadas apenas dos indivíduos que realizaram os exames neste período de estudo.

Os dados foram coletados e repassados sem identificação dos indivíduos, por critérios éticos, para montagem de um banco de dados no Microsoft Excel versão 2016. Posteriormente, foi realizada uma análise estatística descritiva com medidas de tendência central e relativa (média e proporção).

Por lidar com dados diretos de seres humanos, o presente estudo faz parte de um projeto maior intitulado "Análise da profilaxia pós-exposição ao HIV no município de Vitória de Santo Antão - PE", o qual foi submetido ao Comitê de Ética em Pesquisa com Seres Humanos das Faculdades Integradas da Vitória de Santo Antão e foi aprovado com o parecer de número 3.911.518.

\section{RESULTADOS E DISCUSSÃO}

\section{Aspectos sociodemográficos}

No período estudado, foi observado que 356 indivíduos realizavam tratamento no SAE em Vitória de Santo Antão - PE, sendo prevalente o sexo masculino (58,7\%). Esse percentual encontrado corrobora os estudos realizados em outros municípios, como: Aracaju - SE e Maracanaú - CE, sendo prevalente o sexo masculino com $73,03 \%$ e $61,6 \%$, respectivamente. Estudos apontam que esse fenômeno ocorra devido à preferência sexual de muitos homens por parceiros do mesmo sexo ou pela prática bissexual. Além disso, diversos indivíduos do sexo masculino já relataram o não uso de preservativo durante a prática sexual (MENEZES AMF, et al., 2018; NASCIMENTO EB, et al., 2018).

No estudo realizado por Gonçales LF, et al. (2021), no intuito de analisar o perfil epidemiológico de pacientes internados por HIV no Brasil entre os anos de 2010 e 2019, verificou-se prevalência de indivíduos do sexo masculino na faixa etária dos 30 aos 39 anos. Pereira GFM, et al. (2019) estudando os casos de HIV na macrorregião de Ribeirão Preto - SP verificou prevalência no mesmo sexo. Tais trabalhos corroboram os dados do presente estudo, mostrando que existe necessidade de atenção mais específica para com a saúde do homem no tocante às ISTs.

Knauth DR, et al. (2020) aponta em seu estudo que dentre 36 homens entrevistados, somente sete buscaram de forma espontânea o teste anti-HIV. Os demais só realizaram o teste depois de uma ocasião em que houvesse risco para o HIV, como sexo desprotegido ou suspeita de infeção pelo HIV de alguma parceira. 
Os pacientes apresentavam intervalo de idade entre 15 e 85 anos, sendo a faixa etária com maior prevalência dos 33 aos 38 anos, totalizando $18,5 \%$ dos indivíduos, seguida pelas faixas etárias dos 45 aos 50 anos e dos 27 aos 32 anos, com 17,7\% e 16,3\%, respectivamente (Gráfico 1).

Gráfico 1 - Distribuição por faixa etária dos indivíduos com HIV atendidos no SAE de Vitória de Santo Antão - PE no período de 1 de janeiro de 2017 a 30 de junho de 2020.

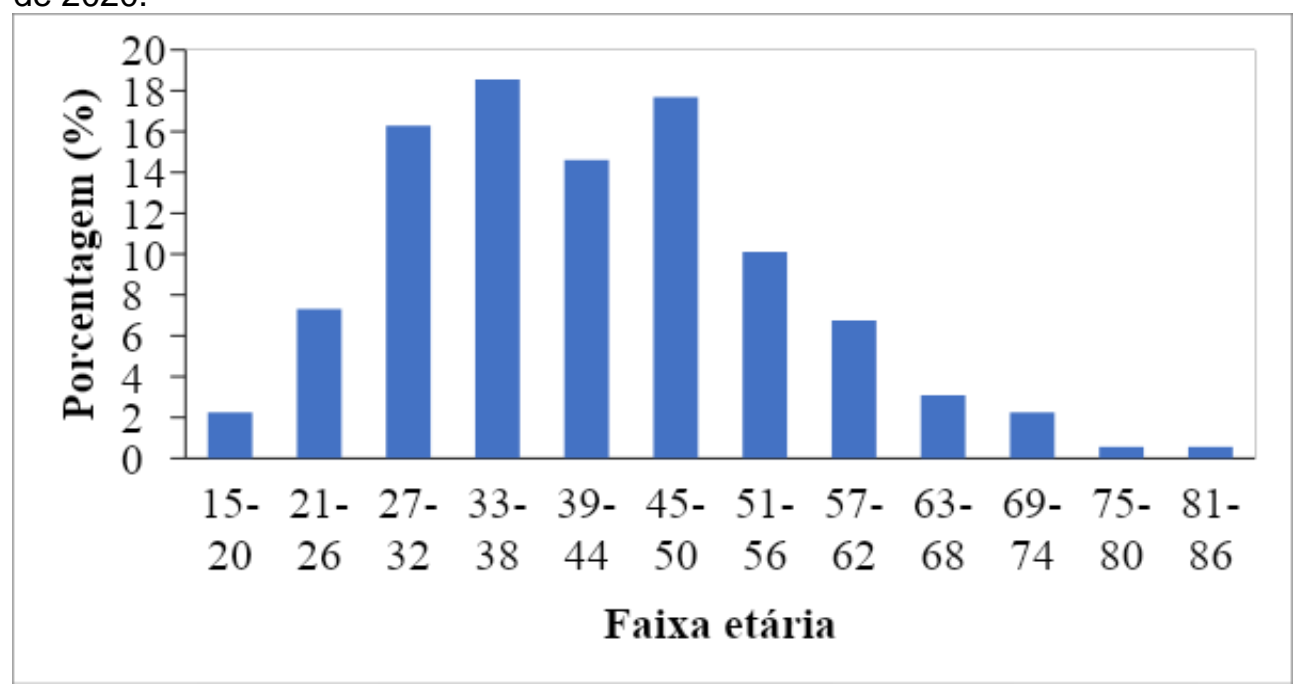

Fonte: Silva MSS, et al., 2021.

Além disso, foi demonstrado que $23,3 \%$ dos indivíduos acometidos com HIV, em tratamento, apresentaram idade superior a 50 anos. É importante destacar este ponto como relevante já que pode estar associado com a diminuição da mortalidade relacionada à infecção com o vírus, devido à eficácia do tratamento antirretroviral.

Entretanto, vale ressaltar que esse grupo etário possui certa vulnerabilidade permanente, devido à diminuição no uso de preservativos por tratarem a relação sexual como algo cotidiano. A ampla distribuição de fármacos com função de melhorar o desempenho sexual e a falta de conhecimento acerca das formas de transmissão também são fatores que corroboram para tais situações (MENEZES AMF, et al., 2018).

Ademais, segundo o Ministério da Saúde, os idosos por julgarem estar fora do grupo de risco de contaminação pelo vírus, adiam a realização do teste de HIV, consequentemente realizando o diagnóstico tardiamente (BRASIL, 2020). É notório que com o passar dos anos a facilidade ao acesso à informação vem melhorando consideravelmente, favorecendo o diagnóstico e o tratamento precoce, porém, essas ações de compartilhamento de informações são, na maioria das vezes, voltadas para adolescentes/jovens adultos, deixando assim, os idosos susceptíveis mais ainda a infecção pelo HIV/AIDS (MENEZES AMF, et al., 2019). Dantas RS, et al. (2020) em um estudo realizado em um centro de referência em HIV de Aracaju - SE, mostrou que dos 309 pacientes cadastrados, 26,8\% tinham idade superior a 60 anos.

A faixa etária também está relacionada como um dos fatores associados à infecção do HIV e sua taxa de mortalidade, diferente dos resultados obtidos neste estudo, os jovens normalmente são enquadrados no grupo de risco, visto que é uma fase caracterizada pela curiosidade e descobrimento, tornando essa população vulnerável a problemas de saúde. Com isso, os casos de contaminação com o vírus HIV em jovens/adolescentes podem estar associados com a ativação da vida sexual precoce e não ter conhecimento sobre as formas de prevenção de IST's (GONÇALES LFR, et al., 2021).

Além disso, o acometimento de jovens/adultos que realizam o tratamento pode ter ocorrido durante o início da vida sexual de forma precoce, notando-se a necessidade de orientação para este grupo acerca dos métodos de proteção e prevenção. Vale ressaltar também que essa população mesmo sendo a que mais está presente em internações no Brasil, normalmente a taxa de mortalidade é maior em pacientes com mais de 70 anos (MELO CJFA, et al., 2020; SANTOS ACF, et al., 2020). 
Com relação aos municípios de residência dos pacientes, observou-se que Vitória de Santo Antão - PE apresentou o maior percentual, correspondendo a 73,9\% dos casos, isto é, esses indivíduos residem e são acompanhados no mesmo município de residência (Tabela 1). Vale destacar que os pacientes podem escolher o local de atendimento e acompanhamento do seu tratamento de acordo com a cidade de preferência. Isso reflete situações para evitar constrangimento, por se deparar com algum profissional ou pessoas conhecidas que estejam sendo atendidas no local.

Indivíduos de diferentes Estados também podem ser atendidos/acompanhados por qualquer SAE. Logo, os dados mostram pessoas de outros Estados que foram atendidos na cidade de Vitória de Santo Antão, seja por razões de mudança de trabalho ou temporada no município. Contudo, estes devem atender os seguintes requisitos: estar cadastrados no Sistema de Controle Logístico de Medicamentos (SICLOM), com dados atualizados, laudo médico e receita de antirretroviral.

Tabela 1 - Relação das cidades onde residem os pacientes em tratamento no CTA/SAE de Vitória de Santo Antão - PE no período de 1 de janeiro 2017 a 30 de junho de 2020.

\begin{tabular}{lcc}
\hline CIDADE & N & $\%$ \\
\hline Cabo de Santo Agostinho - PE & 5 & 1,4 \\
Caruaru - PE & 2 & 0,6 \\
Chã de Alegria - PE & 5 & 1,4 \\
Chã Grande - PE & 4 & 1,1 \\
Cidade Desconhecida & 2 & 0,6 \\
Escada - PE & 2 & 0,6 \\
Feira Nova - PE & 2 & 0,6 \\
Garanhuns - PE & 1 & 0,3 \\
Glória do Goitá - PE & 12 & 3,4 \\
Gravatá - PE & 1 & 0,3 \\
Ipojuca - PE & 4 & 1,1 \\
Itaquaquecetuba - SP & 1 & 0,3 \\
Itaquera - SP & 1 & 0,3 \\
Jaboatão dos Guararapes - PE & 1 & 0,3 \\
João Pessoa - PB & 1 & 0,3 \\
Limoeiro - PE & 1 & 0,3 \\
Moreno - PE & 21 & 5,9 \\
Palmares - PE & 1 & 0,3 \\
Pombos - PE & 8 & 2,2 \\
Recife - PE & 9 & 2,5 \\
Rio de Janeiro - RJ & 1 & $\mathbf{1 0 0}$ \\
São Paulo - SP & 3 & 0,3 \\
Saquarema - RJ & 1 & 0,8 \\
Surubim - PE & 3 & 0,3 \\
Tabuão da Serra - SP & 1 & 0,8 \\
Vitória de Santo Antão - PE & 263 & 0,3 \\
\hline TOTAL & $\mathbf{3 5 6}$ & \\
\hline Fonte: Silva MSS, et at, & & 20 \\
\hline
\end{tabular}

Fonte: Silva MSS, et al., 2021.

O elevado número das pessoas do município de Vitória de Santo Antão - PE em tratamento pode estar relacionado com o aumento populacional, diretamente relacionado ao aumento da infecção pelo HIV. Fernandes NM, et al. (2017) pontua que além da facilidade nas práticas sexuais de forma promíscua e com diversos parceiros, aumentando assim a exposição e facilitando a possibilidade de infecção. 


\section{Aspectos laboratoriais}

Foi avaliada a carga viral de 191 pacientes que realizaram seu último exame no período de março de 2017 a junho de 2020. Observou-se que no período estudado, que foram prevalentes pacientes com carga viral inferior a 50 cópias/ $\mathrm{mL}$, totalizando $80,1 \%(\mathrm{n}=153)$ (Tabela 2$)$.

Tabela 2 - Percentual da carga viral dos exames realizados por pacientes atendidos no CTA/SAE de Vitória de Santo Antão - PE no período de março de 2017 a junho de 2020.

\begin{tabular}{ccc}
\hline Carga viral (cópias $/ \mathbf{m L}$ ) & $\mathbf{N}$ & $\%$ \\
\hline$<50$ & 153 & 80,1 \\
$50-1000$ & 12 & 6,3 \\
$>1000$ & 26 & 13,6 \\
\hline TOTAL & $\mathbf{1 9 1}$ & $\mathbf{1 0 0}$
\end{tabular}

Fonte: Silva MSS, et al., 2021.

Até o final do ano de 2018, foi estimado que cerca de 900 mil indivíduos vivendo com HIV. Nesse período, $66 \%$ fizeram uso da TARV, o que resultou em supressão do vírus em $62 \%$ dos indivíduos, isto é, estes apresentaram carga viral inferior a 1.000 cópias $/ \mathrm{mL}$ (BRASIL, 2019). Caliari JS, et al. (2018) mostrou que $79 \%$ dos pacientes atendidos em um laboratório de Passos - MG, também apresentaram menos de 50 cópias $/ \mathrm{mL}$ (indetectável). Tais dados corroboram o presente estudo e revela a importância do uso da TARV para melhoria da qualidade de vida de pacientes com HIV.

Segundo Santos ACF, et al. (2020), a distribuição dos antirretrovirais está diretamente ligada com a diminuição da mortalidade, estabilização da incidência, diminuição da transmissão vertical, entre outros aspectos positivos. Contudo, a qualidade de vida dos indivíduos acometidos pelo HIV/AIDS não se limita apenas ao tratamento, visto que os aspectos sociais e psicológicos também podem interferir de forma negativa, influenciado a adesão da TARV, já que pode ocorrer o abandono do tratamento pela população acometida devido aos fatores que desencadeiam quadros de ansiedade e transtornos de humor (GONÇALES LFR, et al., 2020).

Nesse sentido, Silva MBG, et al. (2020) em seu estudo, notou que pacientes com carga viral negativa e que apresentavam melhoria na qualidade de vida obtiveram melhores resultados no domínio psicológico, comprovando assim que o tratamento sozinho não é capaz de garantir essa qualidade. Além disso, os aspectos econômicos podem também interferir de forma negativa não só na qualidade de vida como também é um fator relevante para o acometimento de HIV/AIDS, visto que pode promover maior vulnerabilidade na população.

A carga viral indetectável é avaliada com o objetivo de estimar uma possível associação de aderência inadequada e persistência da carga viral acima do limite. Nos pacientes que apresentam contagem abaixo de 50 cópias $/ \mathrm{ml}$, esse fenômeno pode ser utilizado para controlar a adesão à terapia TARV, de forma indireta, visto que valores $<50$ são considerados compatíveis com um tratamento eficaz, pois a adesão ao tratamento visa à supressão da replicação viral (FORESTO JS, et al., 2017).

Nos prontuários de 3 de janeiro a 30 de junho de 2020, foi analisada a contagem de linfócitos TCD4+, no qual o sexo masculino esteve predominante com 52\%, apresentando uma variação de 71 a 339 células $/ \mathrm{mm}^{3}$; já o sexo feminino, apresentou uma variação de 163 a 302 células $/ \mathrm{mm}^{3}$ (Tabela 3).

Tabela 3 - Variação da contagem de linfócitos TCD4+ no período de 3 de janeiro a 30 de junho de 2020 de pacientes atendidos no CTA/SAE de Vitória de Santo Antão - PE.

\begin{tabular}{|c|c|c|c|}
\hline Sexo & $\mathbf{N}$ & $\%$ & $\begin{array}{c}\text { Variação da contagem de } \\
\text { TCD4+ }\end{array}$ \\
\hline Masculino & 10 & 52 & $71-339$ \\
\hline Feminino & 9 & 48 & $163-302$ \\
\hline TOTAL & 19 & 100 & - \\
\hline
\end{tabular}

Fonte: Silva MSS, et al., 2021. 
É importante entender que nos casos em que o sistema imunológico dos pacientes está muito debilitado, há o aparecimento dos sintomas, acarretando a possibilidade de infecções oportunistas, podendo desenvolver a AIDS (COELHO AVC, et al., 2019; CRUZ KO, 2017; MENEZES AMF, et al., 2018).

Em pacientes que não apresentam sintomas da AIDS, cuja contagem varia de 300 a 500 células $/ \mathrm{mm}^{3}$, o risco de adquirir determinadas doenças oportunistas é aumentado devido à escassez de células de defesa no organismo, caso não seja realizado o tratamento precoce. Além disso, a contagem de linfócitos TCD4+ abaixo de 200 células $/ \mathrm{mm}^{3}$ é um fator importante para a ocorrência de óbitos por HIV/AIDS (MENEZES AMF, et al., 2018; FORESTO JS, et al., 2017).

\section{CONCLUSÃO}

Verificou-se que o sexo masculino por ser o mais prevalente, fazem-se necessárias ações de conscientização por meio de redes sociais, ambulatoriais, assistenciais e educativas para esse público. Diante disso, observou-se que o TARV está diretamente relacionado com a melhoria da qualidade de vida do paciente. Isso ficou notório, pois a maioria destes apresentou carga viral abaixo de 50 células $/ \mathrm{mm}^{3}$, o que reflete na boa adesão ao TARV.

\section{AGRADECIMENTOS}

À Secretaria de Saúde, ao Centro de Testagem e Aconselhamento e ao Serviço de Atendimento Especializado do município de Vitória de Santo Antão - PE pela colaboração por meio da disponibilização dos dados para este estudo.

\section{REFERÊNCIAS}

1. ABONGWA LE, et al. Human immunodeficiency virus type 1 (HIV-1) subtypes in the northwest region, Cameroon. Virology Journal, 2019; 16(1): 1-7.

2. BRASIL. Manual técnico para o diagnóstico da infecção pelo HIV em adultos e crianças. 2017a. Disponível em: https://antigo.saude.gov.br/images/pdf/2017/dezembro/27/Manual-Tecnico-para-o-Diagnostico-da-Infeccao-pelo-HIV--Revisao-2017--4-edicao-30102017---Consulta-publica.pdf. Acessado em: 9 de novembro de 2021.

3. BRASIL. Boletim Epidemiológico de HIV/AIDS 2020. 2020. Disponível em: http://www.aids.gov.br/ptbr/pub/2020/boletim-epidemiologico-hivaids-2020. Acessado em: 9 de novembro de 2021.

4. BRASIL. Diretrizes para organização do CTA no âmbito da prevenção combinada e nas redes de atenção à saúde. 2017b. Disponível em: http:/www.aids.gov.br/pt-br/gestores/diretrizes-para-organizacao-e-funcionamento-dos-ctano-ambito-da-prevencao-combinada. Acessado em: 9 de novembro de 2021.

5. BRASIL. Relatório de monitoramento clínico do HIV. 2019. Disponível em: http://www.aids.gov.br/ptbr/pub/2019/relatorio-de-monitoramento-clinico-do-hiv-2019. Acessado em: 9 de novembro de 2021.

6. CALIARI JS, et al. Qualidade de vida de idosos vivendo com HIV/AIDS em acompanhamento ambulatorial Revista Brasileira de Enfermagem. 2018; 71(supl1): 556-65.

7. CARVALHO AC, et al. Perfil epidemiológico de casos de HIV-1 atendidos em um serviço de atenção secundária em Belém-PA no período de janeiro a abril de 2012. Pará Research Medical Journal, 2017; 1(2): e18.

8. COELHO AVC, et al. HIV-1 mother-to-child transmission in Brazil (1994-2016): a time series modeling. Brazilian Journal of Infectious Diseases, 2019; 23(4): 218-223.

9. COUTINHO MFC, et al. Tratamento antirretroviral: adesão e a influência da depressão em usuários com HIV/Aids atendidos na atenção primária. Saúde em Debate, 2018; 42(116): 148-161.

10. CRUZ KO. Perfil epidemiológico de HIV/AIDS na região metropolitana do Cariri cearense: estudo comparativo. Revista E-ciência, 2017; 4(2): 53-62.

11. DANTAS RS, et al. Perfil epidemiológico dos pacientes idosos com HIV em um centro de referência de AracajuSE. Revista de Epidemiologia e Controle de Infecção, 2020; 10(2).

12. FERNANDES NM, et al. Vulnerabilidade à infecção do HIV entre casais sorodiscordantes no Rio de Janeiro, Brasil. Cadernos de Saúde Pública, 2017; 33(4): e00053415.

13. FORESTO JS, et al. Adesão à terapêutica antirretroviral de pessoas vivendo com HIV/AIDS em um município do interior paulista. Revista Gaúcha de Enfermagem, 2017; 38(1): e63158.

14. GONÇALES LFR, et al. Caracterização epidemiológica e clínica do HIV/Aids: associações com a mortalidade. Revista Eletrônica Acervo Saúde, 2021; 13(1): e5293. 
15. KNAUTH DR, et al. O diagnóstico do HIV/AIDS em homens heterossexuais: a surpresa permanece mesmo após mais de 30 anos de epidemia. Cadernos de Saúde Pública [online]. 2020; 36(6): e00170118.

16. MELLO CJFA, et al. Terapia Antirretroviral: principais causas de abandono no estado do Amapá. Revista Eletrônica Acervo Saúde, 2020; 12(8): e3423.

17. MENEZES AMF, et al. Perfil epidemiológico das pessoas soropositivas para HIV/AIDS. Revista de Enfermagem da UFPE online, 2018; 12(5): 1225-1232.

18. NASCIMENTO EB, et al. perfil epidemiológico dos pacientes soropositivos para HIV no Centro de Testagem e Aconselhamento em um hospital municipal de Maracanaú. Revista Expressão Católica Saúde, 2018; 3(2): 57-63.

19. NICOLÁS D, et al. Prevalence, clinical characteristics and outcome of severe primary HIV-1 infection: a prospective cohort study: A prospective cohort study. International Journal of Infectious Diseases, 2019; 88:73-79.

20. OLATOSI B, et al. Towards ending the human immunodeficiency virus epidemic in the US: state of human immunodeficiency virus screening during physician and emergency department visits, 2009 to 2014. Medicine, 2020, 99(2): 18525-18533.

21. SANTOS ACF, et al. Perfil epidemiológico dos pacientes internados por HIV no Brasil. Revista Eletrônica Acervo Saúde, 2020; (48): e3243.

22. SANTOS NS, et al. Virologia Humana. 4aㅡ ed. Rio de Janeiro: Guanabara Koogan Ltda, 2021; 760p.

23. SOUZA HC, et al. Contagem de linfócitos TCD4+ e carga viral em pacientes HIV+ de um laboratório de referência. Revista Brasileira Militar de Ciências, 2020; 6(15): 73-78.

24. SILVA MBG, et al. Qualidade de vida dos portadores de HIV/AIDS no extremo norte do Brasil. Revista Eletrônica Acervo Saúde, 2020; (53): e3757. 